\title{
Pseudoexfoliation Glaucoma in the National Eye Center, Cicendo Eye Hospital, January-October 2012
}

\author{
Rizki Fasa Ramdhani ${ }^{1}$, Elsa Gustianty ${ }^{2}$, Fenny Dwiyatnaningrum ${ }^{3}$ \\ ${ }^{1}$ Faculty of Medicine, Universitas Padjadjaran, ${ }^{2}$ Department of Ophthalmology, Faculty of \\ Medicine, Universitas Padjadjaran/Cicendo National Eye Center Hospital, Bandung, ${ }^{3}$ Department \\ of Anatomy, Faculty of Medicine, Universitas Padjadjaran
}

\begin{abstract}
Background: Pseudoexfoliation syndrome is characterized by the deposition of a distinctive fibrillar material in the anterior segment of the eye. This condition is a major risk factor for development of glaucoma, termed pseudoexfoliation glaucoma (PEXG). The aim of this study was to describe the characteristic and management of PEXG in the National Eye Center Cicendo Eye Hospital.

Methods: A descriptive retrospective study was conducted in October-November 2012 using medical records of PEXG patients in the National Eye Center Cicendo Eye Hospital during January-October 2012.

Results: There were 32 patients (43 eyes) diagnosed as PEXG, most of them were male (78.1\%), age 70-74 years old $(34.4 \%)$ and followed by those in the range of age $65-69$ years old $(21.9 \%)$. Most of the cases were unilateral (65.6\%) decrease of visual acuity less than 3/60 (76.7\%), increase of intraocular pressure (IOP) with majority in the range of 31-40 mmHg (32.6\%) and 41-50 mmHg (32.6\%), Cup/Disc Ratio 0.9-1.0 $(46.51 \%)$ and followed by those classified as majority which were hard to assess because of the presence of opaque media (34.89\%). The type of glaucoma was open angle glaucoma $(88.4 \%)$. The treatment received was a combination of two types of antiglaucoma medication and surgery IOP

Conclusion: PEXG is mostly found in elderly patients. While most of the patients come with high IOP and late stage of the disease IOP
\end{abstract}

Key words: Characteristics, glaucoma, pseudoexfoliation,

\section{Introduction}

Pseudoexfoliation glaucoma (PEXG) develops from the presence of Pseudoexfoliation syndrome characterized by the deposition of a distinctive fibrillar material in the anterior segment of the eye. This condition is a predisposing factor for development of openangle glaucoma. ${ }^{1}$ The PEXG is associated with highly elevated intraocular pressure (IOP), glaucomatous nerve damage, difficulties to cure, and others like subluxation lens. ${ }^{2-7}$

The PEXG was reported to be particularly common in Scandinavia. ${ }^{8}$ The prevalence of PEXG in various population was reported as follows: England (4\%), Germany (4.7\%), Norway (6.3\%), Eskimos (0\%), Russia (12\%), Finland (22\%), Iceland (29\%), Greece $(16.1 \%)$, Australia $(0.98 \%)$, and Iran $(9.6 \%){ }^{9}$ Pseudoexfoliation glaucoma includes as a type of secondary glaucoma with high incidence. Onset of PEXG is rarely found in the age before 50 and most cases occur in their late 60 s and early $70 \mathrm{~s}^{6,7,10}$

The goals of treatment of glaucoma are to reduce IOP and to correct the cause of glaucoma itself. The major therapy medication that reduces IOP is by reducing aqueous humor production. If the drugs cannot relieve symptoms, surgery must be performed. The aim of this study was to describe characteristic and management of PEXG in the National Eye Center Cicendo Eye Hospital.

\section{Methods}

A descriptive retrospective study was conducted using medical records of PEXG patients in the National Eye Center Cicendo Eye Hospital during January-October 2012.

Correspondence: Rizki Fasa Ramdhani, Faculty of Medicine, Universitas Padjadjaran, Jalan Raya Bandung-Sumedang Km.21, Jatinangor, Sumedang, Indonesia, Phone: +6281322498875 Email: rizki.fasa@yahoo.com 


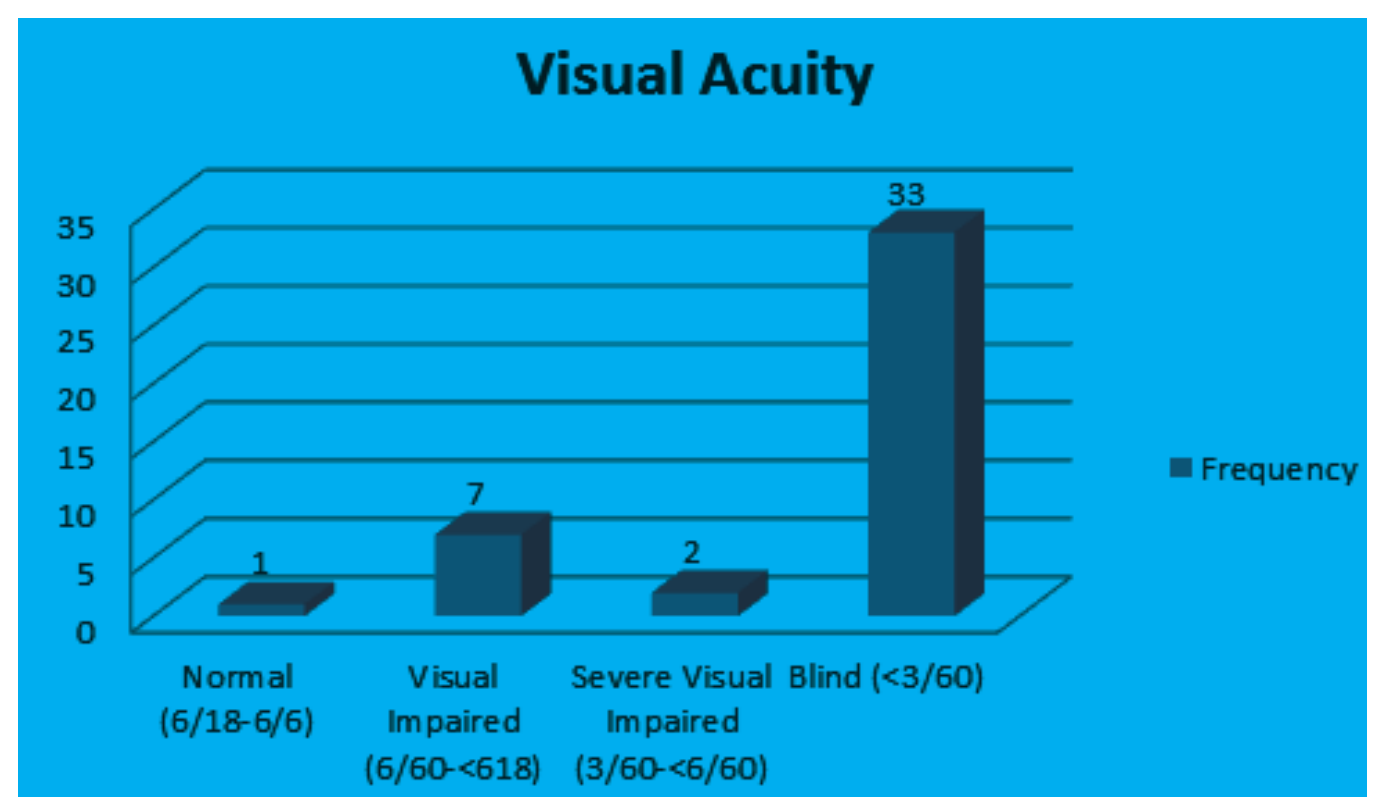

Figure 1 Visual Acuity

From these data, all 32 cases met the inclusion criteria of medical records that contained the patient's characteristics including sex, age, residence, laterality, visual acuity, IOP, cup/disc (CD) ratio in the first admission to hospital, and the anterior chamber angle. There were no cases excluded. These data were presented as frequency distribution.

\section{Results}

Out of a total of 32 patients, 43 eyes were diagnosed with PEXG and included as subjects in this study. The patients were mostly male (78.1\%); most PEXG occurred in the range of age 70-74 years old (34.4\%) and followed by those in the range of age 65-69 years old $(21.9 \%)$. The youngest age of patient with this disease was 50 years old and the oldest was 84 years old. In this study, most of PEXG were unilateral $(65.6 \%)$. Most patients $(76.7 \%)$ had visual acuity $<3 / 60$ based on WHO visual acuity classifications (Figure 1).

Table 1 showed PEXG patients on their first admission to hospital had increase of IOP $>20$ mmHg, with most in the range IOP of 31-40 mmHg (32.6\%) and 41-50 mmHg (32.6\%).

Funduscopy examination which measures cup/disc (CD) ratio indicated most patients were found with CD ratio $0.9-1.0(46.5 \%)$ and followed by those that were classified as hard to assess because of the presence of opaque media $(34.9 \%)$.

There are two types of PEXG, open angle and closure angle glaucoma. Table 3 showed most patients had open angle $(88.4 \%)$. Some data from gonioscopy examination showed these patients could not be assessed (6.9\%) because of presence of cornea edema.

All PEXG patients in this research received treatment. Most patients were given medication only $(68.75 \%)$, while surgical treatment was given to the patient who could not be treated by medication only. The most

Table 1 IOP

\begin{tabular}{ccc}
\hline IOP & Frequency & Percentage (\%) \\
\hline $21-30$ & 10 & 23.3 \\
$31-40$ & 14 & 32.6 \\
$41-50$ & 14 & 32.6 \\
$51-60$ & 4 & 9.2 \\
$61-70$ & 1 & 2.3 \\
\hline
\end{tabular}


Table 2 CD ratio

\begin{tabular}{ccc}
\hline CD ratio & Frequency & Percentage (\%) \\
\hline$<0.7$ & 4 & 9.3 \\
$0.7-0.8$ & 4 & 9.3 \\
$0.9-1.0$ & 20 & 46.5 \\
Hard to asses & 15 & 34.9 \\
\hline
\end{tabular}

Table 3 Anterior Chamber Angle

\begin{tabular}{ccc}
\hline Anterior Chamber Angle & Frequency & Percentage (\%) \\
\hline Open & 38 & 88.4 \\
Closure & 2 & 4.7 \\
Hard to asses & 3 & 6.9 \\
\hline
\end{tabular}

common surgeries were combined surgery $(18.75 \%)$ for treating glaucoma and cataract.

\section{Discussions}

In this study, PEXG mostly occured in elderly people. These findings agree with a study which found PEXG onset was rarely found in the age before 50 , but most cases occurred in their late 60s and early 70s, thus indicating that age was a risk factor of glaucoma. ${ }^{11,12}$

The majority of patients were male. A similar research stated on the prevalence of PEXG in China. Nevertheless, existing theories state that there is no relationship between gender and glaucoma incidence. ${ }^{5}$

In this study most of the glaucoma type ocurred unilateral. Although other studies stated the same, yet the manifestation could be bilateral, therefore it is important to examine and treat another eye. ${ }^{10,11}$

The result of this research showed, most of the patients came when their eyes were already blind. This might happen because the patients had no pain symptoms, therefore they ignored any symptoms which occured and did not realize until it was in the late stage.
Table 1 shows the IOP from PEXG patients were categorized as high $(>21 \mathrm{mmHg})$. Table 2 shows that most patients were with $C D$ ratio of $0.9-1.0$. Some literatures stated that pathogenesis of PEXG and its effect on visual acuity was in parallel with the involvement of the optic nerve as a consequence of high IOP.3 High IOP could damage the optic nerve because of direct pressure or its relation with ischemic theory and/or retinal blood vessel occlusion that can cause decreased visual acuity. ${ }^{3}$

Glaucoma based on its pathogenesis can be divided into open angle and close angle glaucoma. Both mechanisms can occur in PEXG. Table 3 shows that most patients suffered from open angle glaucoma. Another study stated similar result, of which most cases of PEXG was open angle glaucoma. ${ }^{3}$

The purpose of management on PEXG patients was to reduce the IOP. There are some variants of anti-glaucoma drugs with different mechanism of action. Anti-glaucoma drugs are given based on severity of glaucoma and safety for the patient with the consideration of comorbidity such as heart disease, asthma, renal disease, and other diseases. ${ }^{2}$

In conclusion, PEXG occurs in elderly patients and there may be a possible

Table 4 Treatment

\begin{tabular}{ccc}
\hline Treatments & Frequency & Percentage (\%) \\
\hline Medication only & 22 & 68.75 \\
Medication + surgery : & & \\
Trabeculectomy & 4 & 12.5 \\
Combined & 6 & 18.75 \\
\hline
\end{tabular}


relationship between IOP, CD ratio, and decreased visual acuity. Hence for further study, correlations between IOP and visual acuity should be conducted.

\section{References}

1. Arvind H, Raju P, Paul PG, Baskaran M, Ramesh SV, George RJ, et al. Pseudoexfoliation in south India. $\mathrm{Br} \mathrm{J}$ Ophthalmol. 2003;87(11):1321-3.

2. Langston DP. Manual of ocular diagnosis and therapy. 5th ed. Boston: Lippincott Williams \& Wilkins; 2002.

3. Schlote T, Rohrbach J, Grueb M, Mielke J. Pocket atlas of ophthalmology. 1st ed. New York: Thieme; 2006.

4. Rhee DJ, Pyfer MF. The Wills eye manual: office and emergency room diagnosis and treatment of eye disease. 3rd ed. Washington: Lippincott Williams \& Wilkins; 1999.

5. Riordan-Eva P, Whitcher JP. Vaughan \& Asbury's general ophthalmology. 17th ed. San Francisco: McGraw-Hill Companies;
2008.

6. Lang GK. Ophthalmology: a short textbook (flexibook). 2nd ed. New York: Thieme; 2000.

7. Kanski JJ, Bowling B. Clinical ophthalmology: a systematic approach e-book. 7th ed. London: Saunders; 2011.

8. AllinghamRR,LoftsdottirM,Gottfredsdottir MS, Thorgeirsson E, Jonasson F, Sverisson $\mathrm{T}$, et al. Pseudoexfoliation syndrome in Icelandic families. $\mathrm{Br} \mathrm{J}$ Ophthalmol. 2001;85(6):702-7.

9. Foster PJ, Seah SKL. The prevalence of pseudoexfoliation syndrome in Chinese people: the Tanjong Pagar Survey. Br J Ophthalmol. 2005;89(2):239-40.

10. Yanoff M, Duker JS. Ophthalmology. 3rd ed. London: Mosby Elsevier; 2009.

11. Allingham RR. Shields' textbook of glaucoma. 6th ed. North Carolina: Lippincott Williams \& Wilkins; 2005.

12. Young AL, Tang WWT, Lam DSC. The prevalence of pseudoexfoliation syndrome in Chinese people. $\mathrm{Br} \mathrm{J}$ Ophthalmol. 2004;88(2):193-5. 